\title{
Controversies in Pharmacological Treatment of COPD: Introduction
}

\author{
Antonio Foresi $^{\mathrm{a}}$ Dario Olivieri ${ }^{\mathrm{b}}$ \\ a Unit of Respiratory Medicine, AO Istituti Clinici di Perfezionamento, Sesto San Giovanni Hospital, \\ Sesto San Giovanni, and ${ }^{\mathrm{b}}$ Department of Clinical Sciences, Section of Respiratory Diseases, University of Parma, \\ Parma, Italy
}

COPD is a common disease and its incidence continues to rise worldwide, especially in western society. COPD is a progressive (at least in some patients) and heterogeneous disorder, rather than a single entity [1], with important comorbidities, especially in the older populations [2]. Common comorbid conditions, such as cardiovascular diseases, are not only associated with a high mortality rate (approx. 30\% of total deaths) but remarkably affect the health status of COPD patients.

Up until now, there has been a constant tendency to exclude COPD patients with mild or advanced disease from large pharmacological studies, as well as aged individuals. In addition, very little attention, if any, has been given to the presence of cardiovascular comorbidities. Thus, clinical and functional baseline characteristics of populations selected for pharmacological trials have been very poorly defined, and often do not entirely or adequately resemble real-life patients. Despite or perhaps because of these biases, several recent large pharmacological trials in COPD patients have failed to significantly modify the primary outcomes $[3,4]$. However, even if the results of these trials had found that the primary variables were changed to a clinically significant extent, such findings were unlikely to have been easily transferred to the 'real world' population of patients with COPD.
A better understanding of the molecular and cellular mechanisms involved in COPD will help to identify new targets and hopefully new drugs, both for the early and the advanced stages of the disease. However, there is a need to critically revise several controversial issues of the current pharmacological treatment approach.

The present thematic review series focuses on 4 different issues: (1) Do cardiovascular drugs exert a positive effect in patients with COPD? (Samy Suissa); (2) Are inhaled corticosteroids (ICS) useful or detrimental in COPD patients? (Peter Barnes); (3) Is the use of $\beta_{1}$-blockers in COPD still an unresolved dilemma? (Foresi and Olivieri); (4) Do we need different treatments for very elderly COPD patients? (Salvatore Valente).

In this issue, Samy Suissa critically revaluates the results of recent observational studies of statin use in COPD patients. These studies rather surprisingly show that statins have a high efficacy. However, closer analysis has revealed that as previously reported for other treatments, immortal time and immeasurable time biases likely account for reduced mortality.

Peter Barnes reviews the real benefits as well as the potential detriments of long-term ICS treatment in COPD patients. ICS are currently used in combination with LABA (long-acting $\beta_{2}$-agonist) to prevent exacerbations

\section{KARGER}

Fax +4161306 1234

E-Mail karger@karger.ch

www.karger.com (c) 2010 S. Karger AG, Basel

0025-7931/10/0801-0001\$26.00/0

Accessible online at:

www.karger.com/res
Antonio Foresi

U.O.C. di Pneumologia and Fisiopatologia Respiratoria

A.O. Istituti Clinici di Perfezionamento, Presidio Ospedaliero di Sesto San Giovanni

Viale Matteotti 83, IT-20099 Sesto San Giovanni (Italy)

Tel. +390226257 356, Fax +390226257 636, E-Mail antonio.foresi@icp.mi.it 
and to reduce disease progression and mortality. However, with the exception of patients with concomitant bronchial asthma, it appears that ICS are of little benefit to COPD patients. In addition, their prolonged use has some potential detrimental side effects that should be known and considered by clinicians, especially when ICS are administered to older patients at high doses. A consistent detrimental effect on bones and a possible increase in the risk of pneumonia have been recently described in COPD patients treated with ICS.

A treatment previously thought to be dangerous to some patients with COPD is now actually recognized as life-saving $-\beta_{1}$ adrenergic blockers (Foresi and Olivieri). COPD patients do not often receive these medications because of concerns they will worsen airway obstruction. However, when administered to COPD patients, they have been shown to be safe and beneficial in prolonging survival after major vascular surgery and to reduce mortality among patients with concomitant chronic heart failure. A comprehensive knowledge of pharmacological properties of different $\beta_{1}$-adrenergic selective blockers, a close titration of their doses and the assessment of any impairment in lung function by spirometry and gas exchange by lung diffusion for carbon monoxide are likely to improve the safety of these drugs in most patients with COPD.
Finally, this thematic series will review the impact that age-related physiological changes and the frequent presence of comorbidities have on pharmacokinetics and pharmacodynamics of drugs currently used for elderly COPD patients (Salvatore Valente).

These reviews are not only the starting point for better use of currently available drugs, but also for better planning of future pharmacological studies aimed at improving COPD treatment in mild-to-severe, young and old, uncomplicated and complex 'real-world' patients.

References $\quad$ Rennard SI, Vestbo J: The many 'small COPDs': COPD should be an orphan disease. Chest 2008;134:623-627.

2 Padeletti M, Jelic S, LeJemtel TH: Coexistent chronic obstructive pulmonary disease and heart failure in the elderly. Int J Cardiol 2008; 125:209-215.

3 Calverley PMA, Anderson JA, Celli B, Ferguson GT, Jenkins C, Jones PW, Yates JC, Vestbo J, TORCH Investigators: Salmeterol and fluticasone propionate and survival in chronic obstructive pulmonary disease. N Engl J Med 2007;356:775-789.

-4 Tashkin DP, Celli B, Senn S, Burkhart D, Kesten S, Menjoge S, Decramer M, UPLIFT Study Investigators: A 4-year trial of tiotropium in chronic obstructive pulmonary disease. N Engl J Med 2008;359:1543-1554. 